\title{
Sobre un héroe y una tumba. Homenaje a Ernesto Sábato
}

\author{
Daniel-Henri Pageaux • \\ Université de la Sorbonne
}

La muerte de Ernesto Sábato, por previsible que fuera, unos pocos meses antes de cumplir cien años (y veo en esto la última impronta de la ironía sabatiana de la que supo apoderarse lo que llamamos destino), no ha dejado de conmoverme. Profundamente. Es un adverbio muy sabatiano, todos sus lectores lo saben. Sigo considerando a Ernesto Sábato, y repito las palabras con las que abrí el libro que le dediqué (Ernesto Sábato o la literatura como absoluto, París, Tropismes, 1989/1990), como la "conciencia moral" de su país. Y no sólo porque ha prefaciado este terrible libro cuyo título expresaba una fuerte esperanza surgida por entre las tinieblas (Nunca más...) sino porque, con su novelística y sus ensayos, nos ha dejado unos elementos éticos indispensables, dramáticos y sencillos a la vez, que son como otras tantas posibilidades de intuir en nuestra condición humana y en el mundo en que nos ha tocado vivir.

¿Por qué callarlo? Con la muerte de Sábato, de Don Ernesto, como solía llamarlo, es como si se desvaneciera parte de mi vida intelectual, un cuarto de siglo que compartí con su obra y también (fue una suerte de la que soy consciente) con él.

Empezó esta aventura intelectual y humana en 1985 cuando, con motivo de un libro coordinado por A.M. Vázquez Bigi (Sudamérica Planeta, 1985) me animé a escribir sobre el Túnel. Centrándome en la relación estrecha pero conflictiva entre el arte y la vida, puse de manifiesto la fuerte herencia surrealista (más que existencialista) que latía en la novela, rescatando varios artículos que Sábato entregara a la revista Sur y sobre todo el primer texto firmado por él (y también por su amigo el pintor Oscar Domínguez). Era una broma, un verdadero canular que, a pesar todo, fue tomado en serio por Breton

\footnotetext{
- Catedrático emérito de la Sorbona/Paris III. Hispanista y comparatista ha dedicado su labor crítica a las literaturas ibéricas, iberoamericanas y francófonas de las Américas, de África y del Océano Índico. Ha publicado unos veinte libros recopilando sus artículos y conferencias en unos diez volúmenes. Ha fundado y dirige dos colecciones en la editorial l'Harmattan: "Classiques pour demain" y "Palinure. Estudios de literatura general y comparada". Es co-director de la Revue de Littérature comparée y miembro correspondiente de la Academia de las Ciencias de Lisboa.
} 
quien lo citó en su revista Minotaure (nros. 12-13 de 1939), tal vez porque abogaba (pero en clave muy paródica) por "el azar objetivo", cosa muy grata al maestro.

Le interesó a Sábato este rescate de textos antiguos, pero no olvidados. Charlamos bastante sobre estos temas cuando al año siguiente nos encontramos en Estados Unidos, invitados por el ministro argentino de asuntos culturales en Washington, Adolfo Nanclares. Fueron densas sesiones en la Library of Congress y la John Hopkins University. Recuerdo que una estudiante pidió una entrevista a Sábato para el periódico de su universidad y, con rara ingenuidad, le preguntó por qué no había escrito más que tres novelas, lo que consideraba como muy poco. Contestó Sábato con tono tajante (y mucho humorismo): "Uno puede muy bien vivir con un solo libro. Ejemplo: Dios".

En mayo de 1987 me animé a organizar en la Sorbona un homenaje a Ernesto Sábato en compañía de unos colegas, entre ellos Fernando Ainsa y el italiano Antonio Mellis. Hubo una mesa redonda muy cordial bajo el techo dorado de la sala Louis Liard (queda una foto en la cubierta del libro en mi colección "Classiques pour demain”, publicado unos ańos después en 1992 en la editorial l'Harmattan). Le gustó mucho a Sábato el que le preguntara, ya que estábamos en pleno "Quartier Latin", sobre el robo que cometió en la famosa librería Gibert de un libro de matemáticas cuya lectura iluminó varias noches del estudiante más romántico que socialista que iba rumbo a Bruselas. Pero debo confesar que más le agradó el texto que redacté en torno al mito de Orfeo como "mito personal". Me pidió por carta que lo repitiera en francés para el homenaje que se hizo en el Centro Pompidou en 1989 con motivo de su primera exposición de pintura. E intervino para que se publicara en la Nación.

Conservo viva y clara memoria de unas estancias de Sábato en París: le iba a buscar en su Hotel Madison, entre Odeon y Saint Germain des Prés, para una cena. Eran momentos de charla espontánea que no podían sino sorprenderme y encantarme cuando se echaba a ensartar anécdotas y chistes o cuando, ansioso y preocupado, me contaba su entrevista con Cioran o me preguntaba sobre lo que opinaba yo de la última novela de Saramago que trataba nada menos del personaje de Jesucristo.

Se reanudaron estos momentos entrañables en Madrid a raíz de una invitación de la Fundación Sánchez Ruipérez en mayo de 1990 y unos años más tarde, en verano de 1993, en un seminario organizado por la Complutense en San Lorenzo del Escorial. Me pareció original, a pesar de ser un tanto atrevido, hablar sobre la pintura de Sábato y más precisamente en torno a la decisión que tomara de ya no escribir más, dedicándose a fondo a la pintura. Me interesaba desentrañar a mi modo por qué Sábato había querido abandonar la narrativa y hasta sepultarse a sí mismo con el dibujo de la tumba al final de Abaddón, para acceder al reino del color, de las líneas, del volumen y del espacio.

La ventaja de la pincelada sobre la grafía o la palabra parece obvia: con el pincel Sábato hizo surgir unas formas que conllevaban unas posibles significaciones latentes. Desaparecía el hiato doloroso entre la palabra gastada y recreada. Con el color, se aproximaba a una expresión más íntimamente realista, iba a decir más objetiva y subjetiva a la vez; más cratílica, en la medida en que iba creando el pintor sus formas y sus cosas mediante su propio cuerpo. Conseguía con pinceladas lo que siempre intentara con la prosa: hacer surgir la poesía no sólo de las palabras sino también de entre las palabras, lo que él llamara las "reverberaciones" de las palabras. 
Pintar era por lo tanto otra apuesta, en el sentido pascaliano: buscar la sinceridad mediante lo técnico, buscar la plenitud mediante el toque repentino, librarse del epos y alcanzar el instante ideal, esencial, lo poético, el cuncta simul de la creación divina, todo en un solo instante, el Augenblick grato a Goethe, ya que el cuadro que tanto tiempo le costara al artista, provocaba o pretendía provocar en un solo instante algo profundo, decisivo, parecido a la mirada de María hacia la ventanilla: el cuadro era para Sábato el instante fulgurante de lo poético y la pintura una escritura habladora y silenciosa a la vez. Y tal vez pintar haya sido para él volver a encontrar lo que encontrara al emprender el camino de la novela, lo que expresara en una sin terminar: La Fuente muda.

Tengo al alcance de la mano la carta que me mandó el 22 de setiembre de 1993 porque no habíamos podido coincidir en París. Escribía lo siguiente:

Gracias, infinitas gracias, muy querido Daniel, por el envío de su ponencia en El Escorial, profunda e interesante, como todo lo que hace. Ya sabe que me cuesta mucho leer por el peligro siempre presente de agravar mi mal, así que leí muy por encima y encontré que esa "teoría” de los silencios es muy original y que inconscientemente hecho por mí cobra más posibilidades de ser una verdad - ya sabe mi idea sobre las verdades científicas y las verdades poéticas-. Sin duda se trata de ésta porque siempre me he dejado llevar por mi inconsciente, cosa que sorprende a muchos porque creen que eso es atributo de imbéciles, no de alguien que enseńó en la Facultad de Ciencias Físico-Matemáticas, teoría de la relatividad.

Tenga presente que en Uno y el Universo todavía conservaba cierto respeto por la razón que fui perdiendo. Es legítimo escarbar en él gérmenes de mi pensamiento posterior, pero advierto que la base más seria está en Hombres y engranajes, cuando ya me había desembarazado de esos restos. En cuanto a lo que usted llama "silencios" es una gran idea que me ilumina sobre mis vueltas y revueltas. ¡Métale! como se dice aquí en nuestro argot... Un abrazo fuerte y fraternal.

En el momento en que Sábato publicaba sus dos últimos libros, ya había emprendido otros caminos que me habían alejado de su obra. Sólo quiero mencionar el libro organizado por Silvia Sauter (que estaba en el Escorial): Sábato: símbolo de un siglo (Buenos Aires, El Corregidor, 2005) en el que entregué unas páginas sobre Abaddón leído como novela "trascendental", valiéndome de la palabra grata a los románticos alemanes que también les sirviera para definir el aporte original del Quijote: adunar la historia novelesca y la "crítica" de esta historia.

En este año que es el de la muerte de Sábato, figura El Túnel en el programa de oposiciones a cátedra/agrégation en Francia. Me pidieron varias universidades una intervención sobre esta novela. Pero no pude sino repetir lo que había escrito al empezar mi exploración. Entonces quise volver a uno de los modelos favoritos de Sábato: Dostoievski y redacté para un libro de ensayos míos un pequeño texto sobre el tema. Le agradezco a mi colega y amiga Adriana Crolla el haberme persuadido que tradujera este texto adaptándolo, como último homenaje a Ernesto Sábato.

No me parece que sea un homenaje póstumo porque creo en las terribles y misteriosas fuerzas del espíritu.

Son unos breves apuntes sobre una larga fascinación: la de Sábato para con Dostoeivski. 
Profundas son las huellas que dejan en el espíritu del niño o del adolescente los libros que va descubriendo y leyendo. Para el novelista Ernesto Sábato, Dostoievski forma parte de esas lecturas no sólo formadoras sino también fundacionales.

En Antes del fin (Seix Barral, 1999) que presentó como una "especie de testamento", Sábato, después de un largo periodo de silencio, vuelve sobre sus años de aprendizaje, los encuentros que fueron importantes para él y las grandes interrogaciones que recorren sus novelas. Esas le aparecen como "siniestros bailes de enmascarados”. Digamos que la máscara, el velo de la ficción deja paso a unas revelaciones de verdades que sería difícil de decir, de expresar, de "confesar a cara descubierta". Si tuviera que escoger una sola palabra que definiera la obra de Sábato, tomaría la de "confesión", volviendo otra vez a la noción crítica de "novela confesión" con la que intenté dar cuenta de una parte notable de su poética novelesca, en mayo de 1987 cuando quise homenajearle en la Sorbona.

Mi colega en la Sorbona, Michel Cadot, que fue durante unos años Presidente de la Sociedad internacional Dostoievski, intervino sobre la relación de Sábato con el novelista ruso proponiendo varias perspectivas de reflexión. Retomo una de ellas: la imagen para Sábato de Dostoievski como uno de los pocos novelistas de ideas (subrayado de mi colega). Para Sábato, Dostoievski es un "pensador". Pero, e iba glosando a Sábato, un pensador que mezcla sus monstruos nocturnos con ideas teológicas y políticas que atormentan su cabeza (Ensayos, Losada, 1970 801). De modo que la ficción en Dostoievski se presenta como invención y revelación, ficción y confesión. Me parece sumamente importante esa doble dimensión de la novelística de Dostoievski: inventar una ficción que proporcionara unas propuestas esenciales sobre el hombre y también que expulsara, a modo de catarsis, a los demonios que asedian el espíritu y el corazón del hombre. Y con unas palabras esclarecedoras, Michel Cadot definía aquella gran tradición rusa en la que Dostoievski está al lado de Gogol y de Tolstoï como "un arte en el que hombre entero, espíritu, alma y cuerpo, se enfrenta con las fuerzas naturales, el peso de la historia, las trampas de la ignorancia, el desespero ante su finitud, asumiendo plenamente su condición y así rescata y salva la esperanza”.

La alusión a la "esperanza" me parece una iniciativa muy atinada que arroja sobre le universo sombrío y a veces abrumador de Sábato unas luces de confianza en el hombre precario, como decía Malraux. Vale como ejemplo las últimas páginas de Hombres y engranajes (1951) en las que el novelista ensalza la presencia irrebatible de la esperanza en medio de lo que él mismo llama "mi visión sombría de la realidad" (1970 271). Y cita a Kiriloff en los Demonios para justificar ese acto de fe en el hombre: "Creo en la vida eterna en este mundo. Hay momentos en que el tiempo se detiene de repente para dar lugar a la eternidad".

Pensamos en seguida al drama de Juan Pablo Castel, el pintor que cuenta cómo ha matado a la única persona que había comprendido su pintura, María Iribarne. En realidad, quiere día tras día encontrar de nuevo ese intenso momento de comunión que sólo puede proporcionar la obra de arte confundiendo el tiempo de la creación con el tiempo cotidiano. Y vale la pena citar a Sábato, resumiendo su novela en Heterodoxia (1970 337): "Por fin, cuando el protagonista mata a su amante, realiza el último intento de apoderarse de ella, de fijarla para toda la eternidad”.

Castel razona (verbo que por sí sólo resume el drama que vive) como Kiriloff. Pero en esta novela no puede esperar el hombre alcanzar un momento de eternidad 
por medio de la vida sino por la creación artística. El Túnel, por ser una primera novela, es también una novela de la vocación: la "confesión" (una de las primeras palabras de la novela) escrita por Castel después de haber destruido su pintura.

Entonces es cuando podemos entender por qué en el mismo ensayo (Hétérodoxie, Ensayos, 1970 389), Sábato agrega a su "teoría" de la novela la siguiente precisión: "La novela es lo nocturno y, en consecuencia, lo que auténticamente somos. El pensamiento puro es lo diurno y, en consecuencia, lo que deseamos - y logramos - ser. El verdadero Dostoievski no es el moralista de su Diario sino el criminal de Crimen y castigo".

No nos interesa aquí la confusión entre el novelista y su personaje, sino la imagen de un novelista doble que sirve como base de su idea de la novela y como expresión de un doble movimiento fundador: la zambullida en las tinieblas y la subida hacia la luz.

También es de notar que el denso ensayo El escritor y sus fantasmas se cierra con la imagen de un Dostoievski "parricida" que se transforma en escritor "cristiano" (1970 801). Y Sábato vuelve una vez más a su teoría de la novela: después del descenso al mundo de las tinieblas "el arte retorna hacia el mundo luminoso del que se alejó, movido por una fuerza ahora de ex-presión." Es casi una excepción en toda la prosa sabatiana ese guión que remite más bien a las trabajosas traducciones de Heidegger. Y con ese doble movimiento de descenso y subida nos encontramos con otra transcripción del mito de Orfeo.

Para el ensayista Sábato, el novelista es tanto explorador como inventor. El descenso a los infiernos forma parte de esas peligrosas pero necesarias expediciones hacia el "yo profundo" que no remite al "moi profond" de Proust sino al espacio mítico y religioso que llamamos los infiernos o el infierno. Más profundamente vale la pena poner en paralelo la "teoría” de Sabato con las interpretaciones de René Girand cuando analiza la obra del ruso en Critique dans un souterrain (Livre de poche, Biblio 133). Y traduzco: "La obra que junta en vez de esparcir, la obra verdaderamente una cobrará la forma de la muerte y de la resurrección, o sea la forma de la victoria sobre el orgullo. Expulsado el doble, recobrada la unidad, se desvanecen el ángel y la bestia romántica para dar espacio al hombre en su integridad".

En Antes del fin (Seix Barral, 1999 44) Sábato acude a sus años de juventud cuando descubría "a los trágicos rusos que tanto me influyeron”: Dostoievski, Tolstoï, Chejov y Gogol. Pero insiste sobre todo en Crimen y castigo cuya lectura fue a los quince años decisiva. La leyó primero como "novela policial", luego como "novela psicológica" y finalmente como "la mayor novela que se haya escrito sobre el eterno problema de la culpa y de la redención”. Los Hermanos Karamazov, Los Demonios y las Notas desde el subterráneo vendrán después y no dejarán de ser citadas muy a menudo, en particular el tercero. Desde Hombresy engranajes (1951), ese texto sin par cuyo título ha sido traducido de diversas maneras, ha llamado la atención de Sábato por ser una confesión y por desarrollar el tema de la locura expresada en un lugar exiguo que alcanza dimensiones simbólicas. 
Para Sábato, la "literatura actual" a mediados del siglo XXème siècle se fundamenta en una síntesis de lo subjetivo y objetivo (1970 232). Es una manera sencilla y abrupta a la vez para recusar todo tipo de literatura realista que podría valerse del principio estético de la mimesis y desacreditar la literatura comprometida, el realismo socialista que también reiteradamente impugnó. Ahora bien: la tendencia que distingue Sábato empezó con el Dostoievski de las Notas desde el subterráneo en las que el ser humano se complace en hablar de sí mismo: "Voy a hablar de mî" son las primeras palabras que cita al mencionar la obra de Dostoievski. Palabras que suenan como las primeras que escribe Juan Pablo Castel al emprender el relato de su confesión. Pero Sábato añade: "Y en toda su obra, Dostoievski hablará de sí mismo ya se disfrace de Stavroguin, de Ivan o de Dimitri Karamazov, de Raskólnikov y hasta de generala o gobernadora. (...) En toda la gran literatura contemporánea se observa este desplazamiento hacia el sujeto".

Y cita a continuación a Proust, Virginia Woolf, Franz Kafka, Joyce con su monólogo interior y William Faulkner. Añadamos que esta lectura de la historia de la novela es otra manera de abogar por su propia estética y mundo novelesco.

En El escritor y sus fantasmas, Sábato sustenta que el gran escritor es "monomaníaco" como también cualquier gran artista. Y piensa en Van Gogh que al pintar árboles se pinta a sí mismo. Dostoievski abre pues nuevos caminos a la literatura moderna, a la literatura que Sábato considera contemporánea. El novelista ruso legitima las soluciones estéticas del autor de Sobre héroes y tumbas. Verdad es que también valora a Faulkner que supo desterrar al novelista "omnisciente y omnipotente" (1970 233).

Con Dostoievski el escritor va a "submergirse en el yo" (241): "La submersión en lo más profundo del hombre suele dar a las creaciones literarias y artísticas de nuestro tiempo esa atmósfera fantasmal y nocturna que sólo se conocía en los sueños".

Esa tendencia que llama "nocturnidad" no es propia de la literatura. También se nota en la pintura y cita a Chagall, Chirico y Rouault. Concluye asentando que "el alzamiento del hombre contemporáneo contra la tiranía racionalista comienza en las Notas desde el subterráneo".

Paulatinamente Sábato va elaborando una nueva historia de la literatura, del arte, de la cultura al hablar del nacimiento de una "literatura trágica", desde Dostoievski hasta Graham Greene, pasando por Kafka (1970 247): "La gran literatura de nuestro tiempo es eminentemente metafísica y sus problemas son los problemas esenciales del hombre y de su destino".

El arte conoce pues la misma evolución que la literatura. En "Los fantasmas de Flaubert" de 1967, Sábato retoma el caso de Leonardo da Vinci y lo enjuicia de modo personal: la obra, la creación artística de Leonardo dista mucho de su pensamiento matemático (1970 869): "Esas misteriosas grutas que habitan los fantasmas de Leonardo, esa azulinas y enigmáticas dolomitas que entrevemos detrás de sus ambiguos rostros, ¿qué son sino la expresión indirecta del espíritu de Leonardo?”.

¿No recordará aquí Sábato la idea de Leonardo expresada por Valéry según la cual la pintura es cosa mentale? Esta definición, bastante paradójica, remite también a este nuevo realismo subjetivo que Sábato ha definido en sus ensayos y a lo largo de sus novelas.

En otro texto intitulado "Sobre el arte abstracto" (1956), Sábato distingue una tendencia que define como "una rebelión mística de los tiempos modernos" que se realizó a través de espíritus "románticos”, desde Donatello y Miguel Ángel hasta 
Kierkegaard y Dostoievski (1970 433 434): "Encarnaron creciente y tumultuosamente la sublevación del espíritu religioso contra el espíritu tecnolátrico de una civilización burguesa. Sus últimos descendientes los hallamos entre los postimpresionistas como Van Gogh y Gauguin, entre los fauves y los expresionistas, entre los surrealistas y en fin entre aquellos artistas que, aunque surgidos de la abstracción derivaron hacia la realización de objetos concretos, inventados por su propio yo y no en virtud de un proceso de abstracción en el mundo que los rodeaba”.

Leamos esas líneas como otro arte poético y también ético que ilumina la creación novelesca de Sábato.

\section{$* * *$}

Sábato expresa varias veces en El escritor y sus fantasmas su admiración hacia Dostoievski. Son alusiones las más veces breves pero condensan una fuerte y constante fascinación. Admite que España y los países hispánicos saben y quieren expresar su comprensión de los personajes rusos, de los "bárbaros moscovitas" a partir de paralelos entre ambas culturas, sin mencionar al "padre" de esta teoría, el romántico Astolphe de Custine. Es otra manera de oponer la razón occidental y la periferia bárbara (1970 487763 ).

Dostoievski le sirve sobre todo para justificar varias opciones estéticas (1970 483) como la sencillez de la intriga, la utilización de noticias de periódicos como punto de arranque de una novela. Y citaré el recorte de la Razón que encabeza Sobre héroes y tumbas. También le interesan los juicios severos sobre la novelística del ruso que evidencian una incomprensión propia de los genios (1970 755). Aparece pues Dostoievski como otro artista "maldito", lo que fue Van Gogh y lo que es también Castel. Un paralelo puede entablarse entre el ser ficticio y el novelista ruso cuando nota (1970 756): "Entre la locura y el suicidio, fue (paradojalmente) salvado por la prisión”.

Los dos últimos escritos de Sábato, Antes del fin y España en los días de mi vejez (Seix Barral, 2004) ponen de manifiesto muy a menudo el respeto y la admiración hacia el novelista ruso. Nada más que al ver la película de Emir Kustorica "sobre la desaparición de la Yugoslavia” piensa, sin mencionar el título (;Underground.), en la "gran metáfora" inventada por Dostoievski (Antes del fin 121).

En el segundo texto alternan fragmentos de memorias, de discursos, de conferencias y testimonios de escritores españoles. Estos no vacilan en mencionar a Dostoievski cuando se trata de definir el mundo novelesco de Sábato. Sin duda es el poeta, crítico y académico catalán Pere Gimferrer quien mejor expresó en unas pocas frases el espíritu "ruso" de la novelas sabatianas: una poesía de la ciudad que hace pasar de Buenos Aires a San Petersburgo y también "la multiplicidad de las voces" común a los personajes de los dos mundos novelescos. Uno pensará evidentemente en Bajtín que nunca Sábato ha mencionado pero la mayoría de los ensayos citados han sido escritos antes del descubrimiento del crítico ruso por Julia Kristeva a partir de 1967.

No me parece que este enfoque o esa metodología crítica haya sido interesante para Sábato. Admira en Dostoievski (y hasta cierto punto pasa lo mismo con Tomás Mann o Faulkner) el novelista que supo compaginar la filosofía, incluso la metafísica 
con el mundo novelesco sembrando a lo largo de novelas ideas trascendentales que iluminan el mundo precario del hombre ofreciéndole unos instantes de eternidad.

Concluyo, volviendo a una referencia más argentina: la gran novela, según Sábato, poco difiere del humilde tango enjuiciado por el pintoresco Tito de Sobre héroes y tumbas: "Es algo que te parte el corazón pero es una verdad grande como una casa”. El canto, sea del tango, sea de Orfeo, es un canto que funda una nueva visión, un nuevo orden, que da sentido al espacio humano.

¿Por qué tantas veces habló Sábato de "profundidad”? Tal vez sea porque representa lo esencial para el poeta. Y pensamos en esta definición dada por el crítico Jean-Pierre Richard al comenzar su libro Poésie et profondeur: "Se trata de atravesar la profundidad y surgir otra vez de ella, salvado y fraternal”. Así lo hizo, desbrozando el camino, el Vate llamado Orfeo, aquel que a orillas de un río de Grecia supo, otrora, por la fuerza fundadora de su canto, superar su propia tragedia y cantar para los demás.

A fines del siglo XX, a orillas de un Río que demasiadas veces fue río de angustias, de tragedias y de lágrimas, otros hombres han podido oír la honda voz de la novela que asciende desde la profundidad del ser, el canto de Orfeo-Sábato. 